\title{
LEANDER PAULENSIS ORTMANN, 1897 E PERICLIMENES LONGICAUDATUS (STIMPSON, 1860) PRIMEIROS REGISTROS DE CARIDEA (CRUSTACEA, DECAPODA, PALAEMONIDAE) PARA 0 LITORAL DE SANTA CATARINA, BRASIL
}

\author{
IRECE F. MACHADO ${ }^{1,2}$; RODRIGO S. FERREIRA ${ }^{1}$; RONY R. R. VIEIRA ${ }^{1}$ \& FERNANDO D'INCAO ${ }^{1}$ \\ ${ }^{1}$ Universidade Federal do Rio Grande - Instituto de Oceanografia - FURG - Laboratório de Crustáceos Decápodos - Caixa Postal 474, CEP \\ 96201-900 - Rio Grande - RS - Brasil \\ irecemachado@furg.br
}

\section{ABSTRACT}

New records of the palaemonid prawns Leander paulensis and Periclimenes longicaudatus for the South Brazilian coast are presented. The first specie was previously recorded from Maranhão to Paraná coasts, and $P$. longicaudatus from Amapá to São Paulo. The Southern limit of distribution is expanded to Santa Catarina coast.

KEY WORDS: Leander paulensis, Periclimenes longicaudatus, new records, South Brazil

\section{INTRODUÇÃO}

A família Palaemonidae Rafinesque, 1815 é uma das mais representativas e bem sucedidas da infraordem Caridea, estando distribuída por todos os continentes, nas regiões tropicais e temperadas, tendo representantes em ambientes de água marinha, salobra e doce (Holthuis 1952; Bauer 2004). Atualmente no Brasil existem registros de 59 espécies de palaemonídeos (Ferreira 2009).

\section{MATERIAL E MÉTODOS}

Os exemplares foram capturados na enseada

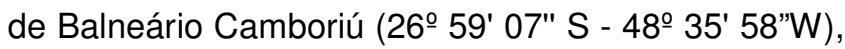
que é uma área tradicional de pesca artesanal no litoral de Santa Catarina. As coletas mensais foram realizadas durante 0 período de maio/2008 a abril/2009, através de arrastos de 15 minutos, utilizando um barco característico da frota artesanal camaroeira (barco tangoneiro - double-rig), redes com malhas de 3,0 cm no corpo e $2,0 \mathrm{~cm}$ no saco e os arrastos realizados a uma velocidade média de 2,0 nós.

Os exemplares de L. paulensis (fêmeas e fêmeas ovígeras) foram coletados durante os meses de julho/2008, enquanto o macho foi coletado em janeiro/2009, já $P$. longicaudatus (fêmea ovígera) foi capturado em maio/2009.

O material analisado (Tabela 1) está depositado na Coleção Científica do Laboratório de Crustáceos Decápodes no Instituto de Oceanografia da Universidade Federal do Rio Grande, Rio Grande do Sul.

Tabela 1- Comprimentos das carapaças para machos e fêmeas das espécies coletadas durante maio/08 a abril/2009, em Balneário Camboriú, SC. * $\mathrm{F}(\mathrm{OV})=$ fêmea ovígera.

\begin{tabular}{|c|c|c|c|c|}
\hline \multirow{2}{*}{ Espécies } & \multirow{2}{*}{$\begin{array}{c}\mathbf{N}^{\circ} \text { de } \\
\text { Tombamento }\end{array}$} & \multicolumn{3}{|c|}{ Comprimento da carapaça $(\mathrm{mm})$} \\
\hline & & Macho & Femeas & $F(O V)$ \\
\hline L. paulensis & FURG-3257 & 5,09 & 4,14- 5,03- 5,91 & 5,08- 5,31- 5,84- 6,03- 6,24 \\
\hline P. longicaudatus & FURG-3256 & & & 3,21 \\
\hline
\end{tabular}

\section{DIAGNOSE}

Leander paulensis Ortmann, 1897 (Figura 1a) Rostro longo e reto, ultrapassando o escafocerito, margem superior com 10 a 14 dentes, dois primeiros colocados na carapaça atrás da órbita e o terceiro colocado bem acima deste limite, margem inferior com cinco dentes. Espinho anterolateral pequeno, atingindo o meio do segundo segmento do pedúnculo antenular. Escafocerito com maior largura na região proximal, com dente distal forte que ultrapassa a margem anterior da lamela. Mandíbula com palpo biarticulado, que não atinge a metade do processo incisivo. Carapaça lisa, com espinho antenal e branquiostegal presentes. Primeiro par de pereópodos delgado, ultrapassando o escafocerito com a extremidade dos dedos. Segundo par de pereópodos mais forte que o primeiro par, 
ultrapassando o escafocerito em todo o comprimento da quela. Terceiro, quarto e quinto pares de pereópodos delgados e com dáctilos simples. Telso com dois pares de espinhos dorsais e dois pares de espinhos na margem posterior (Ferreira 2009).

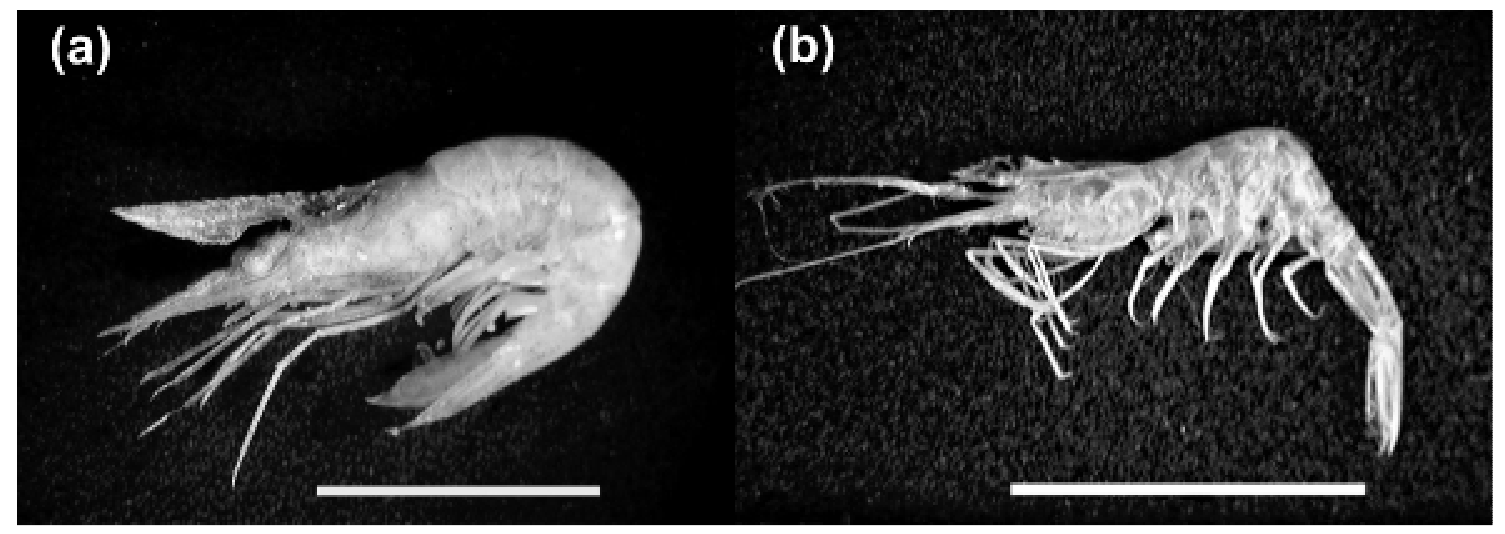

Figura 1-Vista dorsal de (a) Leander paulensis e (b) Periclimenes longicautaus. (Escala $=1 \mathrm{~cm}$ ).

Periclimenes longicaudatus Stimpson, 1860 (Figura 1b) possui rostro curto, reto e bastante alto, atinge o fim do segundo segmento do pedúnculo antenular, margem superior com sete a nove dentes, dois primeiros colocados na carapaça atrás da órbita, margem inferior reta com um ou dois dentes próximos do ápice. Segmento basal do pedúnculo antenular com estilocerito delgado, que não atinge o meio deste segmento, margem anterior deste segmento convexa e bastante pronunciada, com espinho ântero-lateral que ultrapassa tal margem, mas não atinge a metade do segundo segmento do pedúnculo antenular.

\section{LITERATURA CITADA}

BAUER, RT. 2004. Remarkable Shrimps: Natural history and adaptations of the carideans. University of Oklahoma Press, Norman. $282 \mathrm{p}$.

FERREIRA, R.S. 2009. Taxonomia e padrões distribucionais dos camarões marinhos e estuarinos da família Palaemonidae (Crustacea: Decapoda: Caridea) do Litoral brasileiro.
Mandíbula sem palpo. Carapaça apenas com espinho hepático presente. Primeiro par de pereópodos delgado, quase atinge o fim do escafocerito, dedos desarmados e menores que a palma. Segundo par de pereópodos igual na forma e no tamanho, mais robusto que o primeiro par, ultrapassa o escafocerito com parte da palma, dedos menores que a palma. Terceiro, quarto e quinto pares de pereópodos com dáctilos bífidos. Telso com dois pares de espinhos dorsais e três pares de espinhos posteriores (Ferreira 2009).

Dissertação de Mestrado, Fundação Universidade Federal do Rio Grande, Brasil, $153 \mathrm{p}$.

HOLTHUIS, LB. 1952. A general revision of the Palaemonidae (Crustacea Decapoda Natantia) of the Americas. II. The subfamily Palaemoninae. Occ. Pap. Allan Hancock Fdn., Los Angeles, 12: 1-395. 